\title{
Evidence of response of vegetation to climatic change on high elevation sites in the Swiss Alps
}

\author{
Franziska Keller $^{1}$, Felix Kienast ${ }^{2}$, and Martin Beniston ${ }^{1}$
}

1: Department of Geography, University of Fribourg, Switzerland

2: Swiss Federal Institute for Forest, Snow and Landscape Research (WSL), Birmensdorf, Switzerland

Corresponding author: Franziska Keller, Department of Geography, University of Fribourg, Pérolles, 1700 Fribourg, Switzerland; Tel: +41 2630090 26; Fax: +41 2630097 46; franziska.keller@unifr.ch.

\begin{abstract}
Climate change has in the past led to shifts in vegetation patterns; in a future, warmer climate due to enhanced greenhouse-gas concentrations, vegetation is also likely to be highly responsive to such warming. Mountain regions are considered to be particularly sensitive to such changes. In this paper we present an approach to assess the impact of climate change on long-term vegetation plots at the high elevation site of the Schynige Patte, $2000 \mathrm{~m}$ above sea level, in the Bernese Alps (Switzerland).
\end{abstract}

Records of vegetation spanning the period 1928 up till today at two different sites, each with several plots, were considered. The observed change in the species composition was then related to changes in land use and climate. We used daily values of temperature, snow and precipitation from several highelevation weather stations to conduct these analyses.

The correlation between climate and vegetation patterns revealed that species which prefer low thermal conditions move out of the plots, i.e., their frequency of occurrence is negatively correlated with the average number of degree-days over the last six decades. On the other hand, species with higher thermal demands are seen to be invading the plots, i.e., their frequency of occurrence is positively correlated to the average number of degree-days. Nutrient changes - though independent from climate - also seem to play an important role for the observed shifts in species.

Key words: mountain vegetation, climate change, Schynige Platte, Switzerland

\section{Introduction}

The Intergovernmental Panel on Climate Change (IPCC 1996) projects a global warming of the atmosphere of up to $4^{\circ} \mathrm{C}$ compared to 1990 levels by the end of the next century. A number of authors (Barry 1992; Beniston et al. 1996; Beniston 2000) have emphasized the fact that, because of their extreme and climatically-marginal environments, many mountain regions would be highly sensitve to the magnitude and rapidity of projected climatic change. Climatic impacts would be particularly perceptible in the mountain biosphere; shifts in vegetation in response to changing temperature and precipitation regimes are to be expected. The redistribution of current vegetation patterns may, in many instances, result in increases in hazards such as landslides, avalanches, etc. Such risks, related to the reduction of slope stability following changes in forest and plant cover, would place a significant economic burden on many mountain communities.

In mountain regions, the length of the snow season and minimum temperatures are the most important factors for assessing the impact of climate change on high alpine vegetation, because they determine the growth and survival rates of numerous species at high altitudes (Körner 1995). If the growing period were to increase, milder conditions would make it possible for less cold- and snow-resistant plants to grow in these areas, and therefore enhance competition among species.

Individual species will react differently to changes in environmental conditions. In addition, a certain time lag in the response of vegetation to climatic change is to be expected. Model studies, paleoecological evidence and intuition suggest that an increase in temperatures would shift vegetation belts upwards (Peters and Darling 1985). Species which prefer colder conditions would certainly attempt to migrate upwards in order to find the environmental conditions which they are currently used to, but competition between species or the fact that plants already at the top of mountains which have nowhere to migrate to, may in many instances lead to extinction (Halpin 1994). Migration of species, 
as they seek climatic conditions similar to today's, may be hindered by the presence of physical obstacles and the resilience of long-living species in the areas potentially suitable for migration, feigning a quasi-equilibrium of vegetation with climate.

Thanks to a unique 70-year data-set of high-elevation vegetation plots, we were able to undertake an investigation to verify the hypothesis that continued warming in the Alps since the beginning of the $20^{\text {th }}$ Century has led to a more and more detectable uphill shift of temperature-sensitive plants (see also Diaz et al. 1997, Grabherr 1994, Körner 1995). Following conceptual considerations, the present study is restricted to the lowermost level of the functional hierarchy of ecological systems, i. e., individual plants with a short life-span rather than long-lived plant-communities or biomes. This prerequisite of the study follows the reasoning of Neilson (1993), O’Neil et al. (1986), Lawton and Brown (1992) who state that climatic change will first be visible in the species or subspecies composition or in minor changes of the functional pathways. Only greater levels of climatic change would lead to detectable signals in the higher hierarchies of ecological systems. A second prerequisite of the study is a fairly practical one, i.e., it was essential to find well-monitored, long vegetation records to perform the study. One of the very rare sites that fulfils this criterion is the Schynige Platte at $2000 \mathrm{~m}$ a. s. l., in the Bernese Alps (Switzerland). This study area has a long vegetation history that reaches back to the 1930s. Hence the specific research question of the present study are as follows:

- Does the species composition change over time?

- Is a potential change in species composition attributable to climatic change?

- What type of species are shifting in terms of life-history strategies?

- What factors other than climate have a significant influence on the observed change in species composition?

\section{Study area and phytosociological data}

The assessment was performed on experimental plots on the Schynige Platte (figure 1) which have not been treated with any kind of fertiliser since the beginning of the experimental period in the 1930s. The plots are grouped into the area of the Alpengarten with the phytosociological association of the Seslerio-Caricetum and the Lüdiwiese with a Geo montani-Nardetum. Some of the experimental plots were set up in 1928/9 (Lüdi 1940), others in 1933 (Dähler 1993) with subsequent reassessments (phytosociological relevés) in 1939, 1943, 1954, 1972, 1990 and 1997. In the present analysis we disposed of the phytosociological relevés displayed in table 1 . Together with the records gathered in the summer of 1997 by one of the authors, old records from Lüdi (1940), Dähler (1993) and Hegg (personal communication) were used for the analysis.

Tab. 1: Pythosociological relevés available for the present study.

Fig. 1: Location of the study site.

\section{Statistical treatment of phytosociological and climatic data}

\subsection{Multivariate analysis}

Multivariate analysis of the different time steps was used to detect possible changes in the species composition. The MULVA-5 program (Wildi and Orlòci 1996), specifically designed to analyse composition properties of phytosociological relevés as a function of site, climate and other physical properties (Wildi 1993) has been used here.

The relevés of one site were merged in a single database which was then treated as follows: The species scores were transformed to presence-absence and the relevés were arranged according to the year of sampling.

No vector transformation was calculated. To analyse the resemblence pattern of the relevés, a resemblence matrix was calculated using van der Maarel's similarity ratio (van der Maarel 1979). The 
cover-abundance scale of Braun-Blanquet (Braun-Blanquet 1964) had to be transformed to quantitative rank scores according to the suggestion of van der Maarel (1979). In a last step a principal coordinate analysis (PCOA) was calculated. It is a simple numerical technique for multidimensional scaling based on principal component analysis (PCA) methods, but more general (other measurements of similarity than only Euclidean distance; Jongman et al. 1995). It can be defined as a distance-based ordination method in which the distances between sites in the ordination diagram is maximally correlated with the ecological distances.

\subsection{Use of indicator values}

The indicator value concept (Landolt 1977) was employed to check whether a postulated change in composition is either undirected (i. e., whether species with numerous of life-history traits are disappearing or appearing), or directed (i. e., whether only species with certain life-history strategies are disappearing or appearing).

The concept of the indicator values defines ecological profiles (the "realised niche") of each species of the Swiss flora, for 8 climatic and edaphic factors on a standardized scale from one to five. For this study, the indicator value for temperature, continentality, nutrients and $\mathrm{pH}$-reaction were chosen for every species. With this choice, we intended to characterize the life-history strategies of species that cover a wide range of climatic as well as non-climatic parameters.

A probability of presence was calculated for each species and site summarizing all the plots of one site. Consequently, a species that was present in 1933 on all plots of the Lüdiwiese is assigned a value of $100 \%$, while if it is present on only $30 \%$ of all plots in 1997 , the probability of presence is $30 \%$.

For both sites, groups were formed for all the species having identical indicator values. The average probability of presence was calculated such that $100 \%$ was reached if all species of a group with the same indicator value were present in every record on all the plots at one site. Only the presence or absence of the species was considered in this analysis. Thus we used the indicator values only for the stratification of the species, and to express life-history traits of the corresponding species. Calculating the probability of presence in this way makes it possible to check whether there is a tendency for a change in the overall life-history strategies of the observed species, e.g., that more species which prefer warmer climatic conditions can be observed today than in the past.

\subsection{Climatic Data}

Because unfortunately most of the meteorological recording stations in the Bernese Alps do not have any data extending over the period of record of the vegetation plots, we used data from the Säntis for the present study. This is a mountain site located in eastern Switzerland at 2,500 $\mathrm{m}$ above sea level, with daily records in digitized form spanning the period from 1901 up till today. Although the Säntis is located some distance away from the Schynige Platte, it is nevertheless representative of temperature and precipitation in the Alps. Exhaustive analyses were undertaken to ensure that the synchronism of annual and internannual fluctuations observed at Säntis correspond to those observed in the available parts of the records taken from the climatological observing sites in the vicinity of the Schynige Platte (e.g., Grindelwald, Mürren, Interlaken and the Jungfraujoch). The matching of the amplitude and variability of the climatic signals at Säntis and for the corresponding periods in the shorter records in the Bernese Alps is excellent, and justifies the use of the Säntis data as a surrogate for long-term climatological data at the Schynige Platte.

\section{Results}

\subsection{Pronounced shifts in vegetation composition}

The principal coordinate analysis (PCOA) method applied here maximizes the correlation of the distances between sites in the ordination diagram and the ecological distances. Ordination diagrams where the sites (points) are arranged such that those which are graphically close together correspond to 
sites that have similar species compositions. Points that are far apart correspond to sites that are dissimilar in species composition (Jongman et al. 1995).

Fig. 2: Ordination diagram for the Alpengarten site with the following legend:

$\boldsymbol{\Delta}$ 1929, $\square$ 1939, • 1972, 1997

Fig. 3: Ordination diagram for the Lüdiwiese site with the following legend:

$\boldsymbol{\Delta} 1934, \boldsymbol{1} 1941,01954, \mathbf{x} 1990, \bullet 1997$

In the ordination diagrams of figures 2 and 3, symbols identify plots for the same period of the record. The ordination results of the Alpengarten and Lüdiwiese sites clearly show a shifting species composition between the 1930s and the 1990s. Figure 2 illustrates the ordination diagram for the Alpengarten site. It is seen that the 6 vegetation plots have changed considerably their species composition over time. A shift from the middle left of the diagram to the center in the lower part can be observed. The distribution of the points, and therefore the difference in species composition, seems to be greater for the first records than for the more recent ones. The Lüdiwiese site (figure 3) also exhibits a clear shift in species composition since 1934.

\subsection{Upward migration of temperature-sensitive species}

For the Alpengarten site, analysis of the probability of occurrence of warmth-demanding species (indicator values 3 and 4 for temperature) over time shows an increase over the last sixty years (figure 4). On the other hand, probabilities of occurrence of species that tolerate low thermal energy impact (indicator values 1 and 2 for temperature) decrease over the observed period (figure 4). Although the curve for the indicator value 1 shows an increasing tendency since the 1970s, its overall trend has decreased since the 1930s. The probabilities of the indicator values tested with the Kruskal-Wallis test do not always prove significant.

Figure 4: Diagramms of the probabilities of the four chosen indicator values for the Alpengarten; the symbols indicate the following indicator values: $\forall=1, \mathbf{\square}=2, \boldsymbol{\Lambda}=3$, 㸚 $=4, X=5, \boldsymbol{0}=$ average number of degree-days 7 years prior to every vegetation survey.

Analyses for the continentality indicator value support the fact that the probability of occurrence of the species that prefer lower temperature differences increases over time, although the trend is not always significant.

Looking at the nutrient indicator values, the probabilities show a constant increase up to the 1970s, with most species prefering a medium-rich soil. Subsequently, a strong change occurs and the species growing on nutrient-rich soils exhibit a higher occurrence. The reason for this sudden change is not clear, however. The life strategies regarding $\mathrm{pH}$-preferences were balanced in the 1990s on a slightly acid level by the elimination of all species which prefer extreme conditions, i. e., either very acid or basic. These results are statistically significant at both sites.

At the Lüdiwiese site, essentially identical conclusions can be drawn to those for the Alpengarten site. At Lüdiwiese, the probability of finding a species that prefers warmer climatic conditions has doubled since the 1930s, and a tendency for a shift from alpine to subalpine species can be observed. Concerning continentality the study also indicates an increase of species that require milder temperatures with smaller temperature amplitudes.

Correlation analyses between the species indicator values of temperature and those pertaining to nutrients emphasize their independence; this allows to conclude that the observed shift in species composition is as much the result of modified temperature conditions as to changed nutrient availability. As a result, two independent signals of two independent impacts can be detected.

The change in species composition of the experimental plots is most probably due to an influence of changed nutrient amounts and soil acidity; however an influence of changing climatic conditions 
during the $20^{\text {th }}$ Century cannot be excluded. As the climate warming signal increases in the future, the links between vegetation change and temperature change is likely to emerge more clearly in terms of statistical significance.

\subsection{Climatological analyses}

At the Säntis climatological observing site, mean monthly temperatures have risen from about $-2.5^{\circ} \mathrm{C}$ at the beginning of the $20^{\text {th }}$ Century to around $-0.5^{\circ} \mathrm{C}$ in the $1990 \mathrm{~s}$. The increase has been particularly remarkable since the early 1980s; at the beginning of the 1990s, the highest average temperatures of the record were reached. High values were also measured at the end of the 1940s and at the beginning of the 1950s. Only the minimum temperatures show an increasing trend of about $2^{\circ} \mathrm{C}$ since the beginning of the century, while the temperature maxima have remained at a more or less constant level. As reported by a number of studies (e.g., Karl et al. 1993; Beniston et al. 1994; Beniston and Rebetez 1996), in many regions including the Alps, it is principally the rise in minimum temperatures which is responsible for the overall warming this century.

Fig. 5: Number of degree-days with temperatures above $3^{\circ} \mathrm{C}$ and their average temperatures in $1 / 10^{\circ} \mathrm{C}$ at Säntis.

To generate a more physiologically-meaningful surrogate for thermal energy input, we calculated the number of days with mean temperatures exceeding $3^{\circ} \mathrm{C}$ as well as the average temperature of these days. Figure 4 shows the evolution of these two parameters for the Säntis site. An adiabatic temperature correction of $6.5^{\circ} \mathrm{C} / \mathrm{km}$ was applied to account for the altitudinal difference between Säntis (2,500 $\mathrm{m}$ above sea level) and the Schynige Platte (2,000 $\mathrm{m}$ above sea level).

The curves of the degree-days (figure 5) show the same tendencies already explained above, namely warmer periods in the 1940s and cooler average temperatures in the 1970s. The linear trend of the degree-days (solid line) exhibits a systematic increase. The mean temperatures of the degree-days were high in the 1930s, although the curve of the degree-days shows a decreasing tendency. Temperatures for days above $3^{\circ} \mathrm{C}$ were quite high, while the contrary seems to be the case at the end of the $1970 \mathrm{~s}$ and from the 1980s until today, where the average temperatures of the days above $3^{\circ} \mathrm{C}$ are lower but the number of degree-days are high. Days with temperatures just above $3^{\circ} \mathrm{C}$ are more frequent but extreme maximum temperatures occur less often. The trend towards a warmer climate is significant.

Analyses for the changed variability of the climate records from the two periods 1925-29 and 1986-90 show that the fluctuation of the degree-days is much greater in the second period. Especially in the years between 1988 and 1990, no really cold winter periods are recorded at 2,000 m above sea level. There was at least one day with temperatures above $3^{\circ} \mathrm{C}$ one week out of three, which makes earlier plant growth possible. The duration of the summer did not change remarkably. The curves between summer and winter show a much greater variability in the period 1986-90 compared to 1925-29.

Precipitation records of the weather stations in the Bernese Alps do not show any clear trend and every climatological site has its own particular evolution. Snow depth and duration have decreased since the beginning of the century. Years without any snow or only small snow depth have not yet been recorded at elevations as high as $2000 \mathrm{~m}$ above sea level, although this has been observed at low to medium elevations $(<1,200 \mathrm{~m})$ in the late 1980s and early 1990s (Beniston, 1997).

\section{Interactions between climate and vegetation}

In a last step we undertook an attempt to combine the findings from the vegetation surveys with the climatological records. To do so, the average number of degree-days of the seven years prior to every vegetation record (i. e. 1929, 1933, 1939, 1943, 1954, 1972, 1990, 1997) was calculated and compacted with the probabilities of occurrence of any species group formed on the basis of temperature traits (indicator values).

Figure 6: Combined figure of degree-days and temperature indicator value for the Lüdiwiese: indicator value $1, \boldsymbol{\square}=2, \boldsymbol{\Delta}=3$, 路 $=4, \boldsymbol{O}=$ of degree-days of five years prior to vegetation survey. 
Figure 6 and the first graph in figure 4 illustrate the result of these comparisons. Degree-days and probability of plants with high or low thermal requirements, respectively, show clear dependencies, i.e., we observe a negative correlation between the probability of occurrence of species with a lower thermal demand (indicator values 1 and 2), and the average number of the degree-days of the seven years prior to the vegetation surveys. On the contrary, a positive correlation between the probability of occurrence of species with a higher thermic demand (indicator values 3 and 4 ) and the respective of degree-days can be infered.

There is thus a clear relationship between the decreasing probability of occurrence of species prefering cooler conditions on the Schynige Platte, the increasing frequency of species which respond positively to warmer average temperatures and the number of degree-days, and hence the evolution of temperatures this century. These processes can be considered to be a directed change in species composition due to changes in environmental conditions; these changes affect primarily species with either low or high thermal requirements.

From the analyses of the evolution of temperature, it can be concluded that on the Schynige Platte, while average temperatures are slightly higher (essentially due to an increase in minimum temperatures), the amplitude of daily temperature range has become smaller since the 1930s (Rebetez and Beniston 1998) and therefore the trend is towards a milder climatic regime. This is indirectly reflected in the changed species composition observed on the Schynige Platte vegetation plots.

\section{Discussion and conclusion}

In the present paper, we test the hypothesis that enhanced warming in the course of the 20th Century causes plants with high thermal demands to invade areas where they did not previously occur, and plants with low thermal demands to retreat to higher altitudes. However, before drawing any final conclusions, limitations and shortcomings of the present approach need to be addressed:

- Indicator value concept: There is considerable agreement that the indicator values are an expression of the realised rather than the theoretical niche (for details see Austin 1980) and integrates lifehistory strategies at a relatively high level of the complex plant-environment relationships.

- Land-use/climate interaction: The observed changes in the probability of occurrence are attributed to climatic change since there is no correlation between temperature indicator values and nutrient indicator values, i. e., nutrient-sensitive as well as nutrient-tolerant species are shifting places. However, the indicator value for nutrients only accounts for nutrient-related impacts of land use, whereas selective grazing by herbivores is not taken into account.

- Sparsity of data: The study is based on a very limited number of observation points. This, unfortunately, reflects the general lack of long-term monitoring stations for vegetation. Thus, any correlation between the impacts of changing radiative balance of the climate system and plant composition should be viewed with caution.

Taking into account all the limitations listed above, it may be concluded that today a greater number of degree-days are observed compared to the beginning of the century. Plant growth currently takes place earlier in the year than during the early part of the century, because of the shorter winter period. These changes in environmental conditions imply that the probability of finding species which prefer warmer conditions on the Schynige Platte has increased since the 1930s and the ones which favor cooler conditions have decreased. These shifts are independent of any modifications in nutrient availability, and consequently changing climatic conditions appear to be the most likely factor to explain these vegetation changes.

These findings are well in accordance with Grabherr et al. (1994). He showed that on peaks in Austria and Switzerland above an altitude of $3000 \mathrm{~m}$, the number of species has increased up to $70 \%$ since the beginning of the century. At these altitudes, any direct human influence can be neglected, and the colonization of new species is easier because the species pool is not yet full and the competition between the species is weaker. Grabherr et al. (1994) indicate a migration rate of up to $4 \mathrm{~m}$ per decade in the extreme, but on average less than $1 \mathrm{~m}$ per decade. If we compare this with the increase in temperature of 1 to $2^{\circ} \mathrm{C}$ since the beginning of the century, and if plants responded immediately to 
such warming, then a migration rate of up to $15 \mathrm{~m}$ per decade could be expected. Neither the results of this paper nor the ones by Grabherr confirm such migration rates. A possible explanation could be the fact that potential migration rates generally do not match the effective ones, because of a complex set of lagged responses of the system to changes in environmental conditions. However, the future response of vegetation when certain climatic thresholds are reached is open to considerable speculation; this will require far more research of this nature in coming years.

Acknowledgements The authors would like to express their gratitude to Dr. Otto Wildi for the critical review of the statistical part of this paper.

\section{References}

Austin MP (1980) Searching for a model for use in vegetation analysis. Vegetatio 42: 11-21.

Barry RG (1992) Mountain Weather $n$ and Climate. 2nd edn. Routledge, London 392 pp.

Beniston M (1997) Variations of snow depth and duration in the Swiss Alps over the last 50 years: links to changes in large-scale climatic forcings. Climatic Change 36: $281-300$.

Beniston M (2000) Environmental Change in Mountains and Uplands. Arnold/Hodder and Stoughton/Chapman and Hall Publishing Company, London. Approx. 200 pp., in press.

Beniston M and Rebetez M (1996) Regional behavior of minimum temperatures in Switzerland for the period 1979 - 1993. Theor. and Appl. Clim. 53: 231 - 243.

Beniston M, Fox DG, Adhikary S, Andressen R, Guisan A, Holten J, Innes J, Maitima J, Price M and Tessier L (1996) The Impacts of Climate Change on Mountain Regions. Second Assessment Report of the Intergovernmental Panel on Climate Change (IPCC), Chapter 5, Cambridge University Press, pp. $191-213$.

Beniston M, Rebetez M, Giorgi F and Marinucci MR (1994) An analysis of regional climate change in Switzerland. Theor. and Appl. Clim. 49 : 135-159.

Braun-Blanquet J (1964) Pflanzensoziologie, Grundzüge der Vegetationskunde. 3. Aufl. Springer Berlin, Wien, New York.

Dähler W (1993) Langfristige Auswirkungen menschlicher Eingriffe in alpine Vegetation. Geobotanica Helvetica 69 (1993).

Diaz HF, Beniston M, Bradley RS (1997) Climatic Change at high Elevation sites, Kluwer Academic Publishers.

Grabherr G (1994) Climate effects on mountain plants. Nature 369: 448.

Halpin PN (1994) Latitudinal variation in the potential response of mountain ecosystems to climatic change. In: Beniston M (Ed) Mountain Environments in Changing Climate. Routledge Publishing Company, London and New York, pp. 180-203.

IPCC (1996) Climatic Change 1995, The Second Assessement Report of the Intergovernmental Panel on Climate Change (IPCC). Volume 1: Science. Cambridge.

Jongman RHG, Ter Braak OF, van Tongeren OF (Eds) (1995) Data Analysis in Community and Landscape Ecology, Cambridge University Press, 299p.

Karl TR, Jones PD, Knight RW, Kukla G, Plummer N, Razuvayev V, Gallo KP, Lindseay J, Charlson RJ and Peterson TC (1993) Asymmetric trends of daily maximum and minimum temperature. Bull. American Meteorol. Soc. 74 : 1007 - 1023.

Körner Ch (1995) Impact of atmospheric changes on high mountain vegetation. In: Beniston M (Ed), Mountain Environments in Changing Climate, Routledge Publishing Company, London and New York, pp. 155-166.

Landolt E (1977) Ökologische Zeigerwerte zur Schweizer Flora. Veröff. des geobot. Instituts der ETH, Stiftung Rübel, Zürich, Heft 64.

Lawton JH, Brown VK (1992) Redundancy in ecosystems. In: Schulze E-D, Mooney HA (Eds), Biodiversity and ecosystem function. Springer, New York, pp. 2-19.

Lüdi W (1940) Die Veränderung von Dauerflächen in der Vegetation des Alpengartens Schinigeplatte innerhalb des Jahrzehnts 1928/29-1938/39. Special issue in: Rübel E, Lüdi W, Bericht über das Geobotanische Forschungsinstitut Rübel in Zürich für das Jahr 1939.

Neilson RP (1993) Transient ecotone response to climatic change: some conceptional and modelling approaches. Ecol. Appl. 3: 385-395. 
O'Neill RV, DeAngelis JB, Waide JB, Allen TFH (1986) A hierarchical concept of ecosystems. Princeton Univ. Press, Princeton, New Jersey, USA.

Peters RL and JDS Darling (1985) The greenhouse effect and nature reserves: global warming would diminish biological diversity by causing extinctions among reserve species. Bioscience $35: 707$ 717.

Rebetez M and Beniston M (1998) Changes in sunshine duration are correlated with changes in daily temperature range this century. An analysis of Swiss climatological data. Geophys. Res. Letters 25: 3611-3613.

van der Maarel E (1979) Transformation of cover-abundance values in phytosociology and its effects on community similarity. Vegetatio 39: 97 - 114.

Wildi O, Orlòci L (1996) Numerical exploration of community patterns. A guide to the use of MULVA-5. 2nd Ed., SPB Academic Publishing bv, The Hague, 171p. 
Tab. 1: Pythosociological relevés available for the present study.

Fig. 1: Location of the study site.

Fig. 2: Ordination diagram for the Alpengarten site with the following legend:

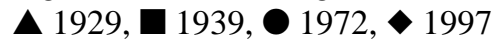

Fig. 3: Ordination diagram for the Lüdiwiese site with the following legend:

A 1934, —1941, ○ 1954, * 1990, 1997

Figure 4: Diagramms of the probabilities of the four chosen indicator values for the Alpengarten; the symbols designate the following indicator values: $\boldsymbol{\nabla}=1, \boldsymbol{\nabla}=2, \boldsymbol{\Delta}=3$, 路 $=4, \times=5, \boldsymbol{0}=$ average number of degree-days 7 years prior to every vegetation survey.

Fig. 5: Number of degree-days with temperatures above $3^{\circ} \mathrm{C}$ and their average temperatures in $1 / 10^{\circ} \mathrm{C}$ at Säntis.

Figure 6: Combined figure of degree-days and temperature indicator value for the Lüdiwiese: indicator value $1, \boldsymbol{\square}=2, \boldsymbol{\Delta}=3$, 路 $=4, \boldsymbol{O}=$ average number of degree-days of 7 years prior to vegetation survey. 
Alpengarten

\begin{tabular}{|l|l|l|}
\hline number of the analysed plots & assessement dates & source/author \\
\hline $15,19,20,21,22,24$, & 1928,1938 & Lüdi (1940) \\
\hline & 1972 & Hegg(pers. communication) \\
\hline & 1997 & Keller \\
\hline
\end{tabular}

Lüdiwiese

\begin{tabular}{|l|l|l|}
\hline number of the analysed plots & assessement dates & source/author \\
\hline $\begin{array}{l}\text { 316, 317, 318, 319, 320, 321, 325, } \\
\text { 329, 333, 337, }\end{array}$ & $\begin{array}{l}1934,1941,1954, \\
1990\end{array}$ & Dähler (1993) \\
\hline & 1997 & Keller \\
\hline
\end{tabular}

Tab. 1: Pythosociological relevés available for the present study. 


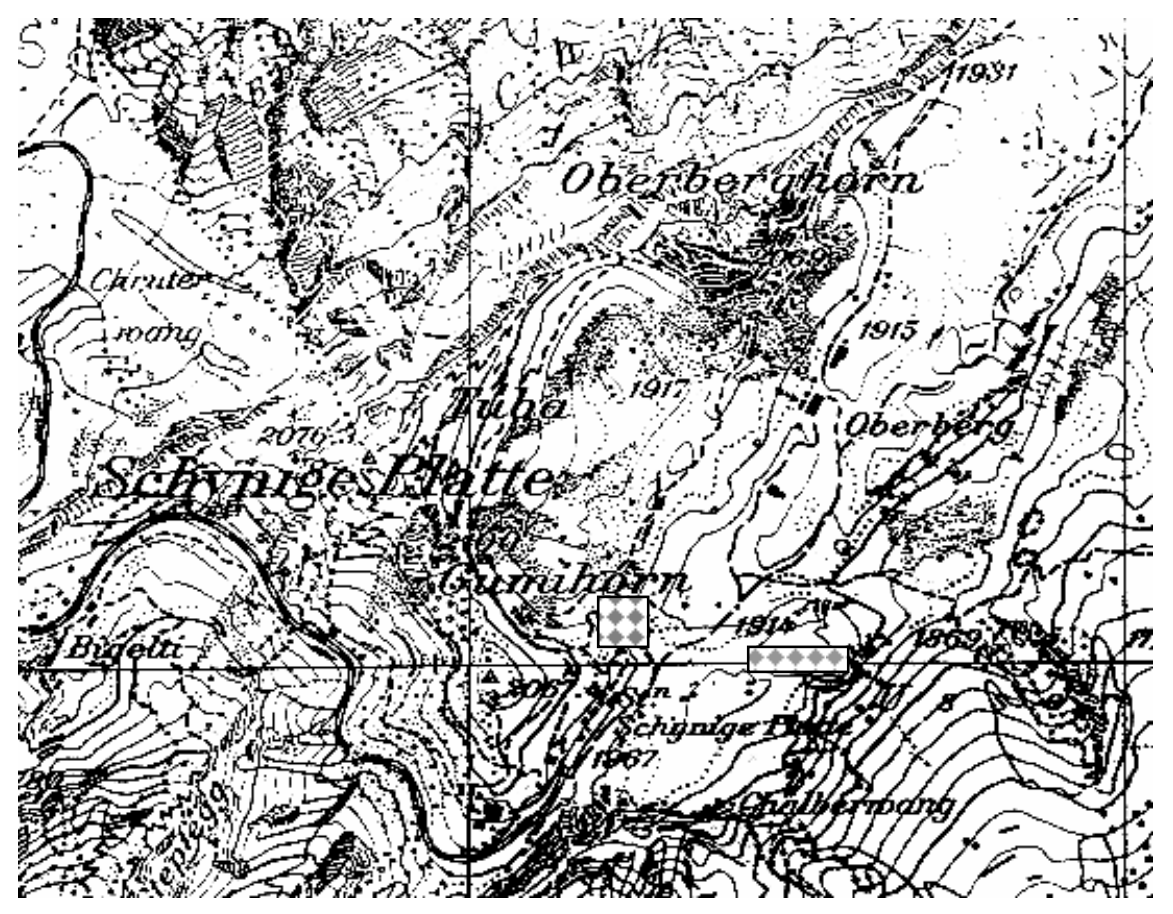

Fig. 1: Location of the study site 1:12'500 (@ of the Federal Office of Topography). 


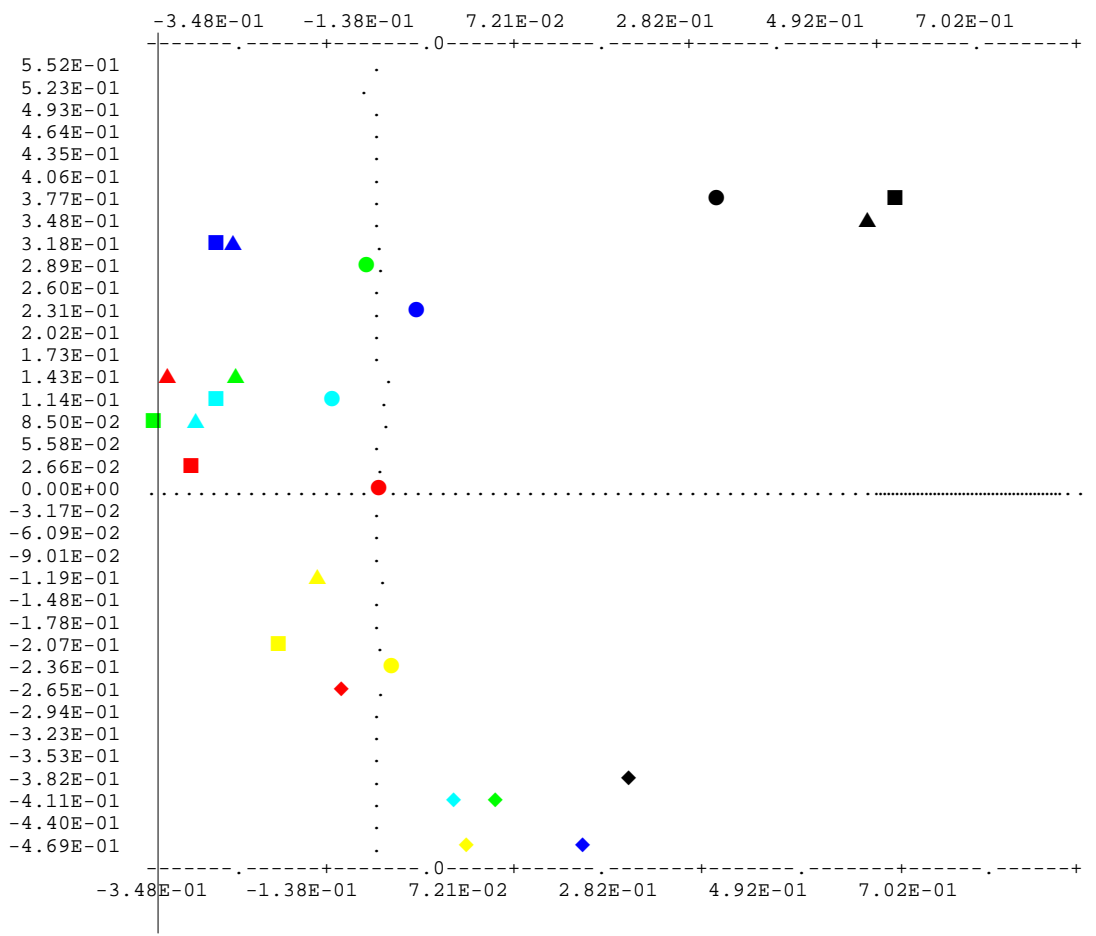

Fig. 2: Ordination diagram for the Alpengarten site with the following legend: \ 1929, —1939, • 1972, 1997 


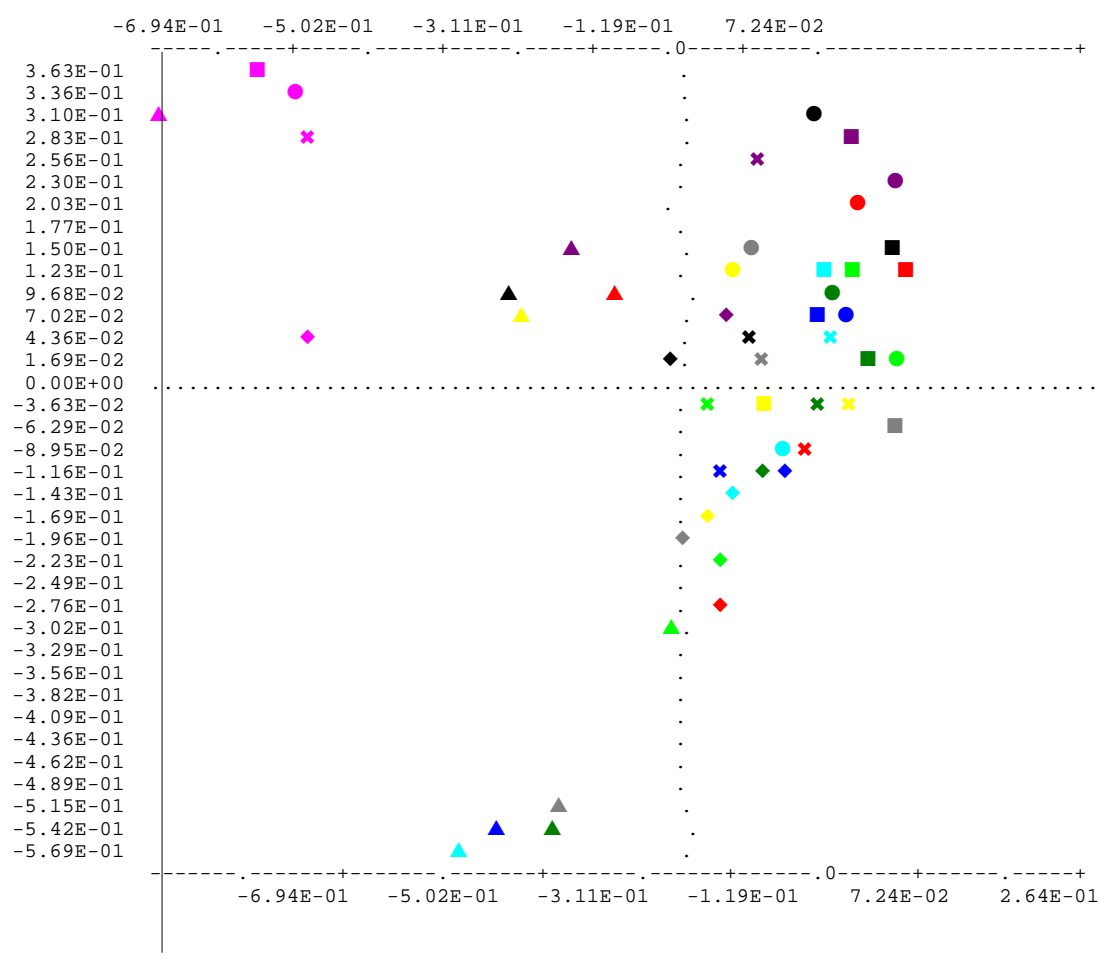

Fig. 3: Ordination diagram for the Lüdiwiese site with the following legend: A 1934, — 1941, 1954, * 1990, 1997 
T emperature and degree days Alpengarten

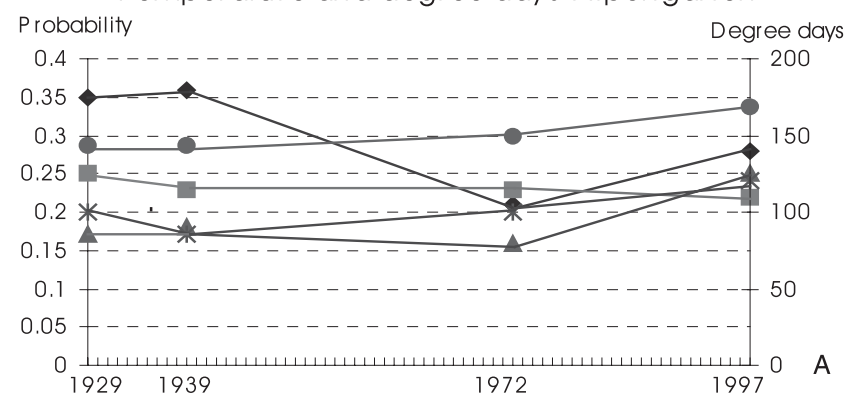

Nutrients Alpengarten

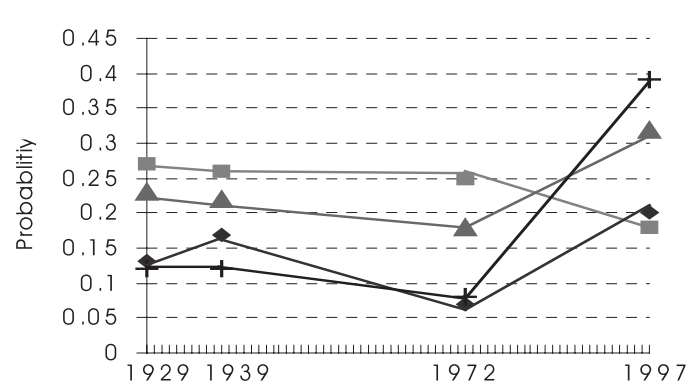

Continentality Alpengarten

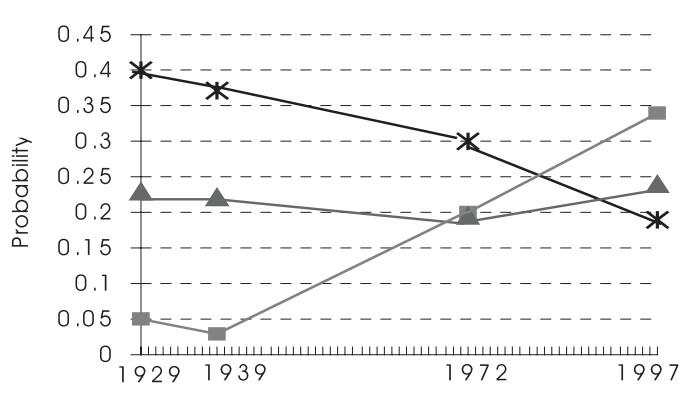

R eaction Alpengarten

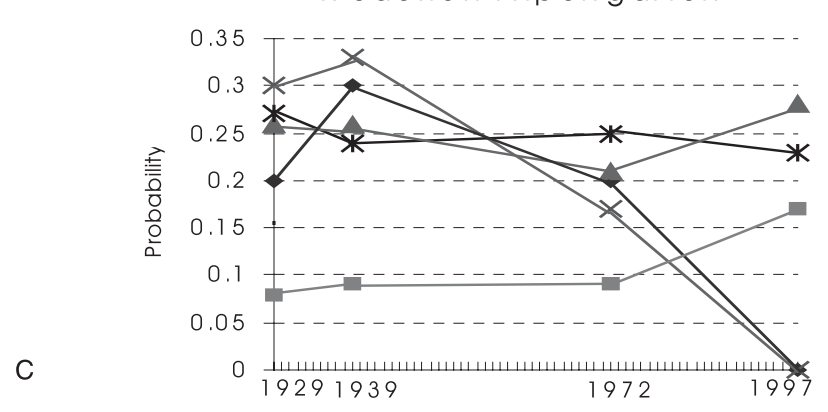

Fig. 4

Probabilities of the four chosen indicator values for the Alpengarten. Symbols indicate the following indicator values: $1 ; \mathbf{\square} 2$; $\boldsymbol{\Delta} 3$; ${ }^{*} 4$; X 5 ; average number of degree-days 7 years prior to every vegetation survey 


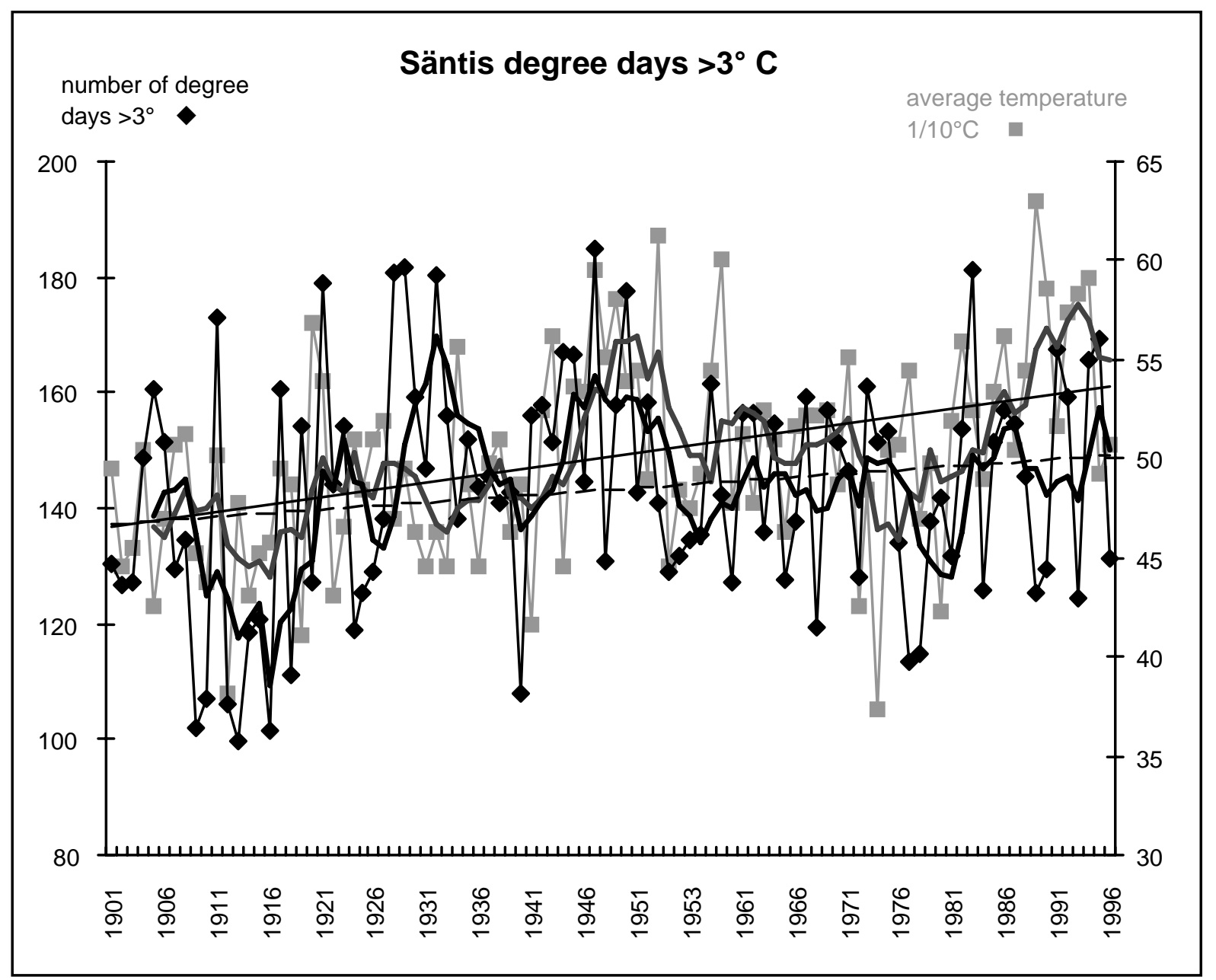

Figure 5: Number of degree-days with temperatures above $3^{\circ} \mathrm{C}$ and their average temperatures in $1 / 10^{\circ} \mathrm{C}$ for the Säntis. 


\section{Degree days and temperature}

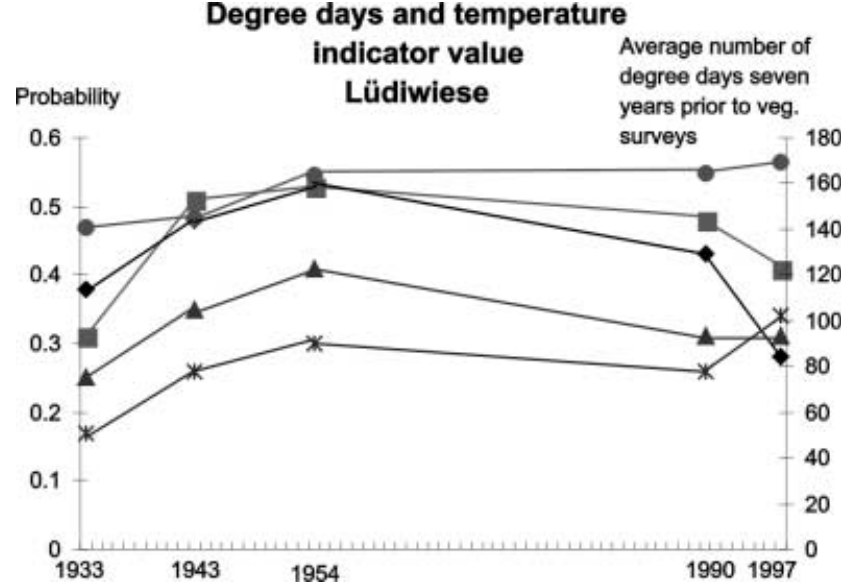

Fig. 6

Combined figure of degree-days and temperature indicator values for the Lüdiwiese area. Symbols indicate the following indicator values: $1 ; \boldsymbol{\square} 2 ; \boldsymbol{\Delta} 3$; ${ }^{\star} 4$; $\boldsymbol{O}$ average number of degree-days of 7 years prior to vegetation survey 